\title{
On the observed changes in upper stratospheric and mesospheric temperatures from UARS HALOE
}

\author{
E. Remsberg \\ Science Directorate, NASA Langley Research Ctr., Hampton, VA, USA \\ Received: 11 May 2007 - Revised: 11 September 2007 - Accepted: 1 February 2008 - Published: 28 May 2008
}

\begin{abstract}
Temperature versus pressure or $T(p)$ time series from the Halogen Occultation Experiment (HALOE) of the Upper Atmosphere Research Satellite (UARS) have been extended and re-analyzed for the period of 1991-2005 and for the upper stratosphere and mesosphere in 10-degree wide latitude zones from $60 \mathrm{~S}$ to $60 \mathrm{~N}$. Even though sampling from a solar occultation experiment is somewhat limited, it is shown to be quite adequate for developing both the seasonal and longer-term variations in $T(p)$. Multiple linear regression (MLR) techniques were used in the re-analyses for the seasonal and the significant interannual, solar cycle (SC-like or decadal-scale), and linear trend terms. Plots of the amplitudes and phases for the interannual (QBO and subbiennial) terms are provided. A simple SC-like term of 11-yr period was fitted to the time series residuals after accounting for the seasonal and interannual terms. Highly significant SC-like responses were found for both the upper mesosphere and the upper stratosphere. The phases of these SC-like terms were checked for their continuity with latitude and pressurealtitude; the larger amplitude responses are directly in-phase with that of standard proxies for the solar flux variations. The analyzed, max minus min, responses at low latitudes are of order 0.5 to $1 \mathrm{~K}$, while at middle latitudes they are as large as $3 \mathrm{~K}$ in the upper mesosphere. Highly significant, linear cooling trends were found at middle latitudes of the middle to upper mesosphere $(-1.5$ to $-2.0 \mathrm{~K} / \mathrm{dec}$ de $)$, at tropical latitudes of the lower mesosphere (about $-0.5 \mathrm{~K} /$ decade), and at $2 \mathrm{hPa}$ (of order $-1 \mathrm{~K} /$ decade). Both the diagnosed solar cycle responses and trends from HALOE for the mid to upper mesosphere at middle latitudes are larger than simulated with most models, perhaps an indication of decadal-scale dynamical forcings that are not being simulated so well.
\end{abstract}

Keywords. Atmospheric composition and structure (Pressure, density, and temperature) - Meteorology and atmospheric dynamics (Climatology; Middle atmosphere dynamics)

Correspondence to: E. Remsberg

(ellis.e.remsberg@nasa.gov)

\section{Introduction}

Efforts to understand the seasonal and longer-term variations of the temperature distribution of the mesosphere (Beig et al., 2003; Laštovička, et al., 2006) have been ongoing for three to four decades using ground-based lidar and in situ rocket measurement techniques, respectively (see e.g. Keckhut et al., 2005; Kubicki et al., 2006). Although those techniques are providing good quality time series of temperature data above geophysical observing stations, it has been difficult for analysts to resolve the atmospheric temperature response to the forcing of the 11-yr solar cycle and then the underlying trends due to changes in the so-called "greenhouse gases" using datasets from fixed, local sites (e.g. Hampson et al., 2006). It has also been difficult to use station data to verify model simulations of changes in the zonal mean temperature (e.g. Akmaev et al., 2006; Kodera and Kuroda, 2002; Gruzdev and Brasseur, 2005). Satellite measurement techniques are providing datasets on the seasonal and interannual variations of the zonal mean mesospheric temperature (e.g. Fleming et al., 1990; Shepherd et al., 2005), but up until recently they have been limited to time spans that are considerably shorter than a solar cycle.

Remsberg (2007) reports on findings from time series of temperature versus pressure (or $T(p)$ ) based on 95,900 sunrise (SR) plus sunset (SS) measured profiles from the HALogen Occultation Experiment (HALOE) satellite experiment (Russell et al., 1993). This 14-year (1991-2005) $T(p)$ dataset extends for more than one complete solar cycle, making it possible to consider separating long-term trends from the effects of the solar forcing. HALOE obtained an exo-atmospheric look at the Sun as part of the signal normalization procedures for each of its measured atmospheric profiles. In addition, in-orbit calibration measurements of the performance characteristics of the HALOE instrument were obtained throughout its mission lifetime. No significant changes were found that affect the fidelity of its time series of $T(p)$ (Gordley et al., 2006).

Published by Copernicus Publications on behalf of the European Geosciences Union. 


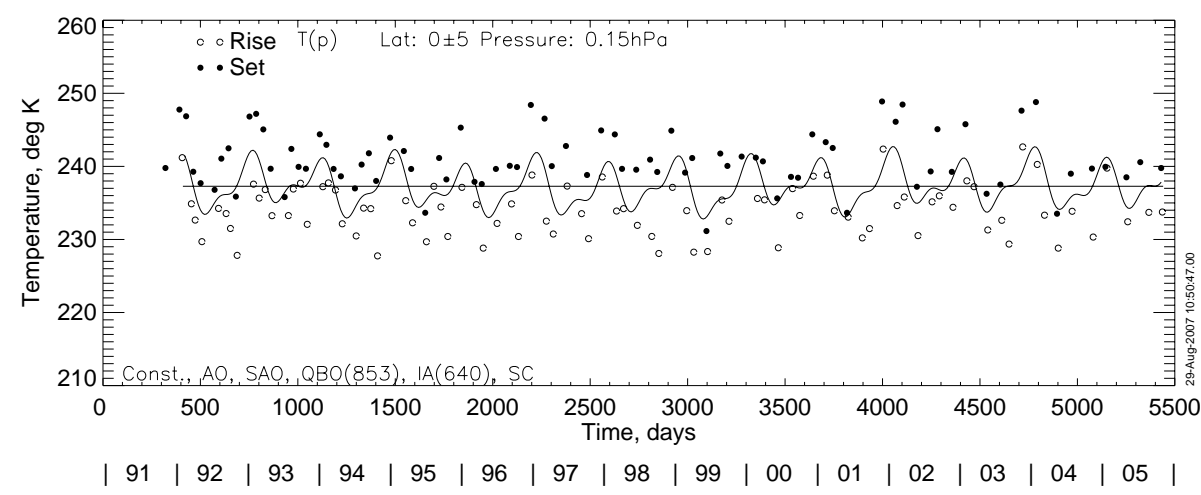

Fig. 1. Time series of zonal average SS (solid circles) and SR (open circles) temperatures (K) from HALOE measurements at the equator and the $0.15-\mathrm{hPa}$ level of the mesosphere (near $62 \mathrm{~km}$ ). Terms for the multiple linear regression (MLR) model fit are listed at the lower left. The oscillating curve is the fit for the complete MLR model, while the straight line is the value of the constant term.

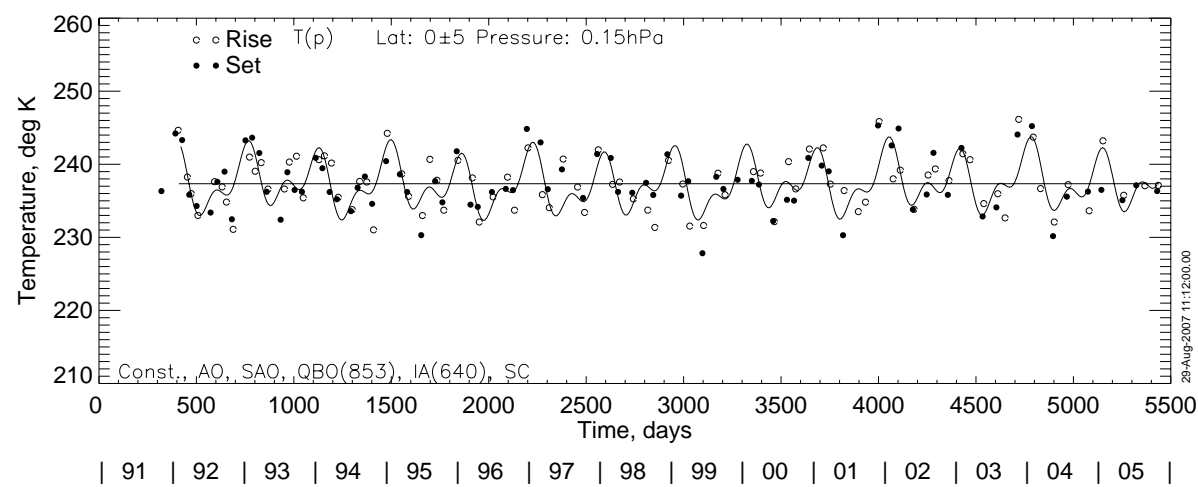

Fig. 2. As in Fig. 1, but the SS and SR points have been adjusted by half the mean SS/SR difference and then refit with the MLR model.

The HALOE profiles of $T(p)$ are based strictly on retrievals of its $2.8-\mu \mathrm{m} \mathrm{CO}_{2}$ channel transmission profiles above about the 3-hPa altitude. The forward model for the HALOE transmission accounts for the annual changes in the atmospheric $\mathrm{CO}_{2}$ throughout its 14-yr lifetime. At the 5-hPa altitude and below, the $T(p)$ information is based entirely on the analyses from the NOAA Climate Prediction Center (CPC), as provided to the UARS Project. Above the 0.007$\mathrm{hPa}$ altitude there is a tie-in to the MSIS-90 climatology. Vertical resolution of the individual retrieved $T(p)$ profiles is of order $3.5 \mathrm{~km}$. Time series of zonal average $T(p)$ data have been generated from the profiles and analyzed for 13 latitude zones from $60 \mathrm{~S}$ to $60 \mathrm{~N}$ and for 16 pressure levels from $2 \mathrm{hPa}$ (near $43 \mathrm{~km}$ ) to $0.007 \mathrm{hPa}$ (near $82 \mathrm{~km}$ ) - a total of 208 separate time series for this analysis. The time series analyses herein have been conducted for constant pressure levels, rather than for constant altitude levels, in order to make it easier to analyze for the vertically local effects of the seasonal variations and to delineate the diabatic changes in the $T(p)$ profiles due to forcings from the solar flux and to the radiative cooling from $\mathrm{CO}_{2}$.
This paper is complementary to and extends the material of Remsberg (2007), as outlined below. Section 2 reviews briefly the approach that was taken for the analyses and the nature of the differences between time series of the sunset (SS) versus the sunrise (SR) points. Section 3 contains plots of the phases of the seasonal cycle terms and provides examples of the seasonal temperature distributions at $20 \mathrm{~N}, 40 \mathrm{~N}$, and $60 \mathrm{~N}$ for qualitative comparisons with climatologies developed from ground-based station measurements. Section 4 contains plots of the zonal mean distributions of the amplitudes of the quasi-biennial and subbiennial terms. Profiles of the phases of those terms are also shown for selected latitudes. Section 5 then reviews the findings from HALOE for the SC-like and the trend terms and compares them with some recent model results and with other datasets. Section 6 discusses the findings in Sect. 5, particularly for those regions where the phase or magnitude of the 11-yr term disagrees with that for a direct, solar forcing mechanism. 


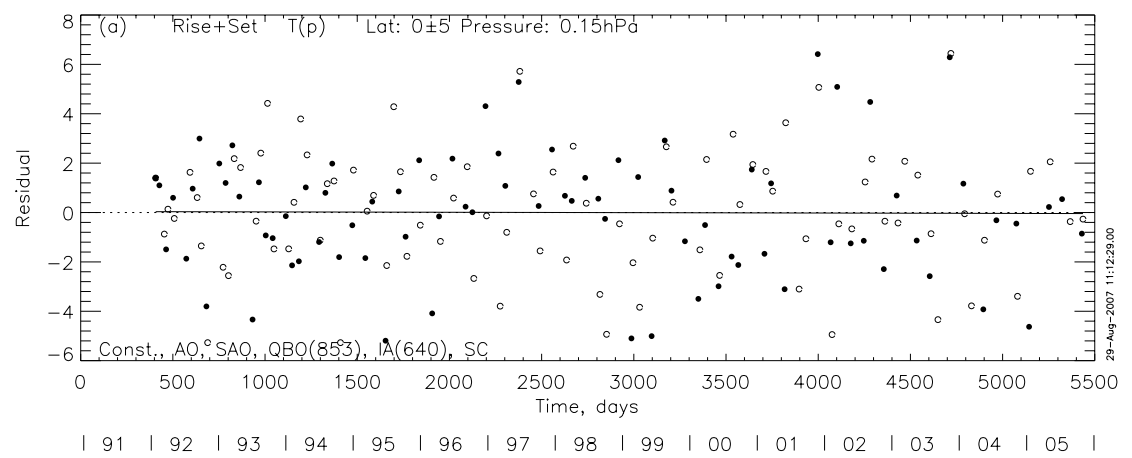

Fig. 3. Temperature residuals (K) for the MLR model fit to the data of Fig. 2.

\section{Data analysis approach}

The limb occultation measurements of the Sun by HALOE occur at two local times. Remsberg et al. (2001), Remsberg and Deaver (2005), and Remsberg (2007) have analyzed the time series of SS plus SR ozone and/or temperature data at selected latitudes and pressure-altitudes. SS and SR measurements occurred, on average, about every 25 days for a given 10-degree wide latitude zone, although at certain latitude zones and times of the year they occurred within only a few days of each other. As an example, the locations of the SS and SR tangent points are shown in Remsberg et al. (2001) for each day of 1995. A 25-dy sampling frequency is quite adequate for characterizing even the shorter-period, semi-annual variations in $T(p)$ that are especially significant for the mid mesosphere at low latitudes.

Figure 1 is an example of one such time series for the Equator and the 0.15-hPa level of the mid mesosphere (at about $62 \mathrm{~km}$ ). The oscillating curve is the multiple linear regression (MLR) fit to the time series of about 200 points and is based on a model that includes annual (AO), semi-annual (SAO), quasi-biennial (853-dy or QBO), sub-biennial (640dy or IA), and 4017-dy (11-yr or SC) terms. The straight line is the constant term from the model. The average SS minus SR bias in the data is $6.9 \mathrm{~K}$ at this level and latitude, and it is due to the effects of tides to first order. Although the MLR model fit for the seasonal terms in Fig. 1 is reasonable, its short-period (or noise-like) residuals are considerable and tend to limit the accuracy of the fit for the small-amplitude, long-period terms. Remsberg (2007) adjusted the SS and SR points by half their average difference and then re-combined them as shown in Fig. 2. As a result, he obtained better continuity for the time series points and an improved fit for all the MLR model terms. The residuals for the model fit of Fig. 2 are shown in Fig. 3, and the solid horizontal line is the linear fit to those residuals.

The points in Figs. 1 and 2 consist generally of alternating occurrences for SS and SR at a zone of latitude. The combined time series of Fig. 1 has a lag-1 autocorrelation coefficient that is highly negative (AR1 $=-0.53$ ). After mak- ing the SS/SR adjustment AR1 becomes weakly positive (AR1=0.13) for the series of Fig. 2, indicating just a slight point-to-point memory for the non-diurnal, zonal mean state of the tropical mid-mesosphere. Thus, the analysis sequence is: (1) obtain an initial fit to the adjusted time series, (2) determinate its AR1 coefficient, (3) transform the terms of the model to account for that memory, and then (4) perform another fit using those transformed terms to obtain their uncertainties. As customary, the final residuals of Fig. 3 were checked for any significant structure. More details on these steps are given in Remsberg (2007).

Because the seasonal ( $\mathrm{AO}$ and $\mathrm{SAO}$ ) cycles in the time series generally have much larger amplitudes than those of the longer period terms (e.g. QBO-like, subbiennial, and solar cycle (or SC-like)), it is important to account for those seasonal cycles with very good accuracy. After the seasonal terms were fit to the data, the residuals of this simple model were Fourier-analyzed to resolve any longer-period structure (Remsberg, 2007). QBO-like (853-dy) and subbiennial (640dy) cycles were highly significant for most latitudes and pressure altitudes. The subbiennial period arises as a result of the difference between the AO and QBO terms (Dunkerton, 2001). Those two interannual terms were included in the MLR models. Further analyses were conducted at each latitude and pressure-level for sinusoidal SC-like terms of 4017dy (11-yr) period and for linear trend terms. A simple fit to the data residuals was the basis for the assessment of the phase of the 11-yr term. The combined set of terms was used for the final MLR models.

\section{Seasonal terms}

Remsberg (2007) contains tabulations of the amplitudes and phases of the semiannual (SAO) and annual (AO) terms, plus zonal mean cross section plots of their amplitudes, from $60 \mathrm{~S}$ to $60 \mathrm{~N}$ and from 0.007 to $2 \mathrm{hPa}$, and they agree very closely with those reported by Randel et al. (2004) from HALOE for the period 1992-1999. The $T(p)$ profiles are based only on the NOAA/CPC analyses below about the 5-hPa level, 


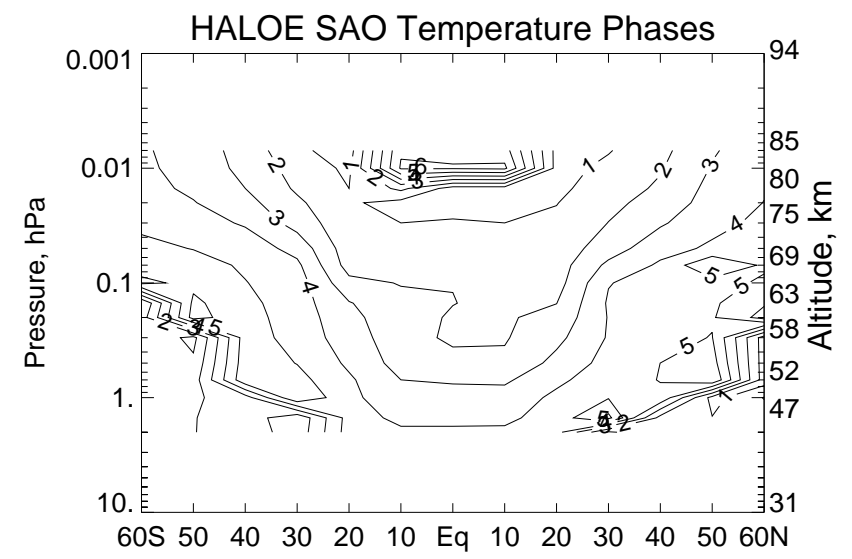

Fig. 4. Contour plot of the zonal average temperature phase (month of year) for the maximum of the first cycle of the semi-annual oscillation (SAO) term. Contour interval is 1 month. Altitude scale is approximate.

although the bottom-up retrieval scheme for the HALOE $T(p)$ is effectively free of that lower bound influence by $2 \mathrm{hPa}$ (Remsberg et al., 2002). In most respects the annual average and seasonal terms from HALOE are similar to those reported previously from temperature climatologies obtained with other satellite datasets (e.g. Barnett et al., 1985; Shepherd et al., 2004; Huang et al., 2006). Some differences should be expected depending on whether the comparison climatologies are referenced against pressure or altitude or whether they are based on low versus medium vertical resolution measurements. The climatology herein is somewhat unique because the HALOE SS and SR temperatures have been adjusted for the average effects of tides. However, there may be slight biases for the AO amplitudes, and especially for the SAO amplitudes at low latitudes, because this first order adjustment for the combined HALOE time series does not consider seasonal variations of the tides, as reported by Huang et al. (2006). Note also that the present analysis approach does not allow for an SAO term that varies in amplitude (or phase) from its first to its second cycle. The seasonal and annual mean temperatures from these HALOE analyses are also essentially free of the small but significant interannual and solar cycle terms because those terms were accounted for in obtaining the final MLR models of this study.

Plots of the phases of the SAO and $\mathrm{AO}$ terms are given in Figs. 4 and 5, respectively, for the range of pressure-altitudes of the upper stratosphere and mesosphere. Figure 4 shows the phase (in days) for the first SAO maximum. It propagates downward with a hemispherically-symmetric lag that increases from low to middle latitudes. The SAO has only a weak phase tilt with altitude in the mesosphere at middle latitudes. Conversely, the AO phase of Fig. 5 has very little tilt at low latitudes in the mesosphere until one ascends to near the $0.05-\mathrm{hPa}$ level. AO phases are hemispherically antisymmetric, as expected for the annual cycle forcing. Some

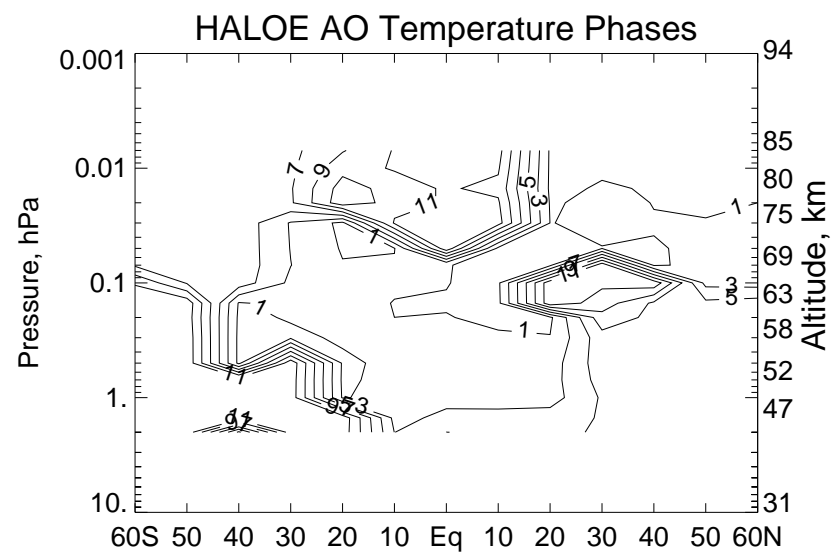

Fig. 5. As in Fig. 4, but for the phase of the annual oscillation (AO) term. Contour interval is 2 months.

of the small-scale gravity waves are effectively filtered by the winds in the stratosphere. However, both the planetary waves and the gravity waves propagate upward and equatorward more effectively at equinox, "break" and deposit their energy in the uppermost mesosphere, and contribute to the generation of the tropical SAO (Baldwin et al., 2001).

The SAO and AO amplitudes and phases and the annual average temperature values that have been reported here and in Remsberg (2007) can be used to generate the seasonal variation of the zonal mean $T(p)$ for a given latitude. As examples, Figs. 6 and 7 show the seasonal variations for $T(p)$ at $20 \mathrm{~N}$ and $40 \mathrm{~N}$, respectively. They compare very favorably with the seasonal variations of temperature versus altitude (or $T(z)$ ) obtained from ground stations at Hawaii $(19.5 \mathrm{~N}$, 204 E) and in France (44 N, 6 E) using ground-based lidar instruments (see Plate 1 in Leblanc et al., 1998). In Fig. 6 the effect of the SAO at $20 \mathrm{~N}$ shows clearly in April as a change from maximum temperatures at the stratopause to minimum values in the upper mesosphere. The second SAO cycle is apparent by late October. In Fig. 7 for $40 \mathrm{~N}$ the AO cycle is paramount; the effect of the SAO does not extend to the middle and high latitudes.

Seasonal variations can also be generated from the HALOE data for the higher latitudes of 50 and 60 degrees because HALOE sampled those latitudes often enough to define the dominant AO term, at least. Figure 8 shows the data time series and its MLR model for $0.01 \mathrm{hPa}$ and $60 \mathrm{~N}$. It is apparent that although there are fewer total points in this high latitude time series, the simple MLR model is fitting them well. Minimum temperatures are of order $160 \mathrm{~K}$ and occur in mid summer for this latitude band $(55 \mathrm{~N}$ to $65 \mathrm{~N})$. There is a broad maximum of about $205 \mathrm{~K}$ in winter, punctuated by a weak SAO signal. One can also see clearly the effects of about a 4 day per year retrogression of the HALOE tangent point sampling (e.g. Kawamoto and Shiotani, 2000) by observing the sequence of springtime SR points from 19972001 and then the springtime SS points from 2001-2005. 


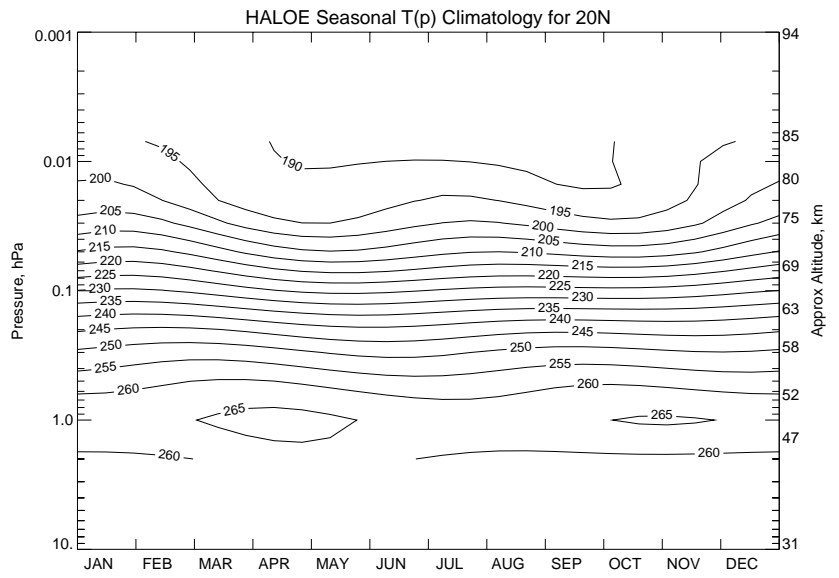

Fig. 6. Seasonal variation of the HALOE $T(p)$ climatology for $20 \mathrm{~N}$. Contour interval is $5 \mathrm{~K}$.

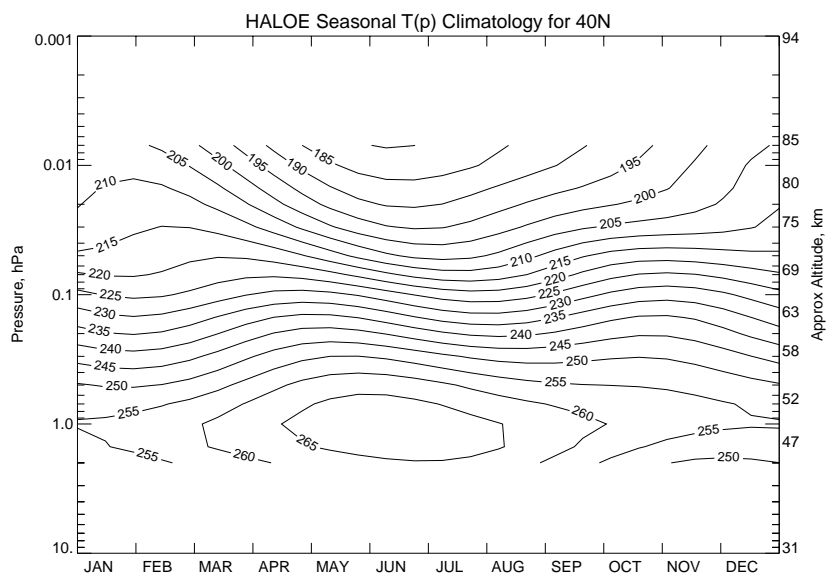

Fig. 7. As in Fig. 6, but for $40 \mathrm{~N}$.

Figure 9 is the seasonal $T(p)$ climatology at $60 \mathrm{~N}$, based on the analyzed terms of the MLR models for the range of pressure altitudes. Note that the zonal mean HALOE results for $40 \mathrm{~N}$ in Fig. 7 and for $60 \mathrm{~N}$ in Fig. 9 do not show the effects of the large localized winter stratospheric warmings or mesospheric coolings that are often pronounced in seasonal plots at specific station locations (Remsberg et al., 1994) or in hemispheric maps from daily satellite data (e.g. Remsberg et al., 2003).

\section{Interannual terms}

Remsberg (2007) contains a tabulation of the amplitudes of the two primary interannual terms having periods of 853 days (28-month, quasi-biennial or QBO) and 640 days (21-month, subbiennial or IA), respectively. He determined those dominant periods from a Fourier analysis of the time series residuals after accounting for the seasonal terms. Although he was unable to resolve highly significant interannual terms for ev-

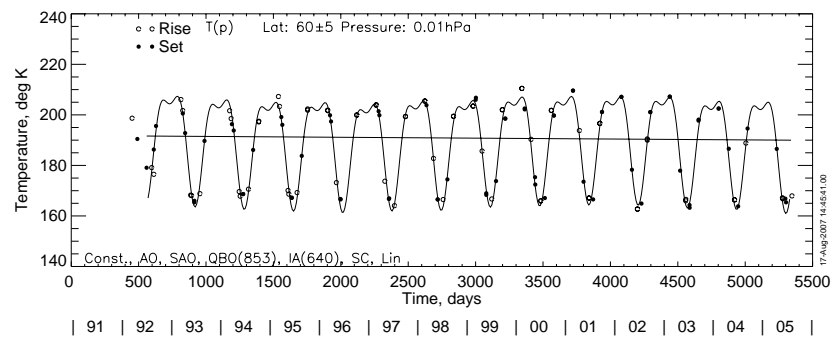

Fig. 8. MLR model fit to the HALOE $T(p)$ time series points at $60 \mathrm{~N}, 0.01 \mathrm{hPa}$.

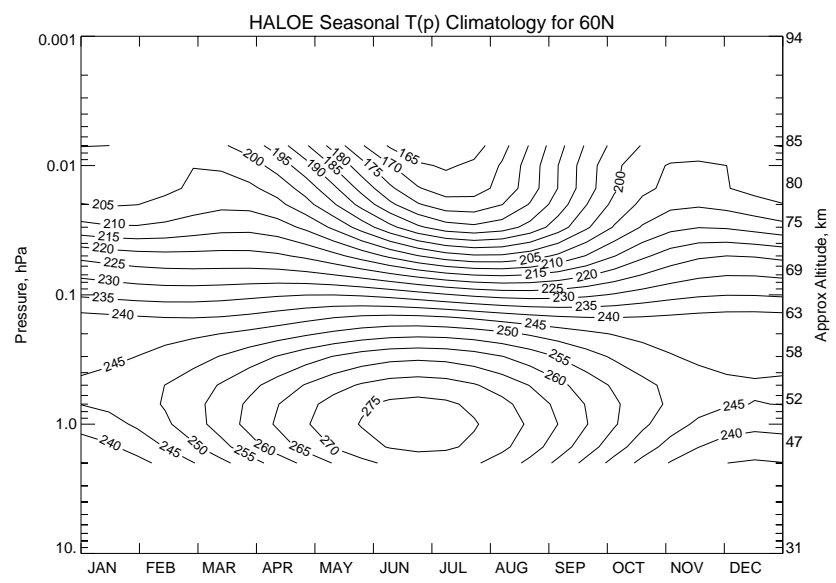

Fig. 9. As in Fig. 6, but for $60 \mathrm{~N}$.

ery latitude and pressure-altitude, both terms are included in the models for each of the 208 zonal mean grid points in this study.

Figure 10 shows the distribution of the amplitudes for the QBO-like terms. They are relatively small (of order $1.2 \mathrm{~K}$ or less) throughout the tropical and subtropical upper stratosphere and mesosphere. Amplitudes grow to $1.4 \mathrm{~K}$ at about $0.01 \mathrm{hPa}$ at the Equator and are in reasonable accord with the pressure-altitude for the maximum winds associated with the mesospheric QBO (Burrage et al., 1996; Baldwin et al., 2001). It is noted that HALOE could not really define the top boundary of the equatorial maximum at $0.01 \mathrm{hPa}$ because its retrievals are being merged with the MSIS climatology above that level. Larger amplitudes $(0.9 \mathrm{~K}$ to $1.5 \mathrm{~K})$ are present at 40 to 50 degrees of latitude in both hemispheres, and their location in the upper mesosphere agrees with that reported by Huang et al. (2006) from the SABER dataset.

It is important to remember that the amplitudes of the QBO terms from HALOE are being obtained with respect to pressure (not altitude) surfaces, and that the upper mesosphere QBO at low latitudes is primarily due to the dynamical forcings from gravity waves (Baldwin et al., 2001). Therefore, any atmospheric temperature response should be somewhat adiabatic and not so apparent in pressure coordinates. With that in mind, the QBO amplitudes of Fig. 10 can be compared 


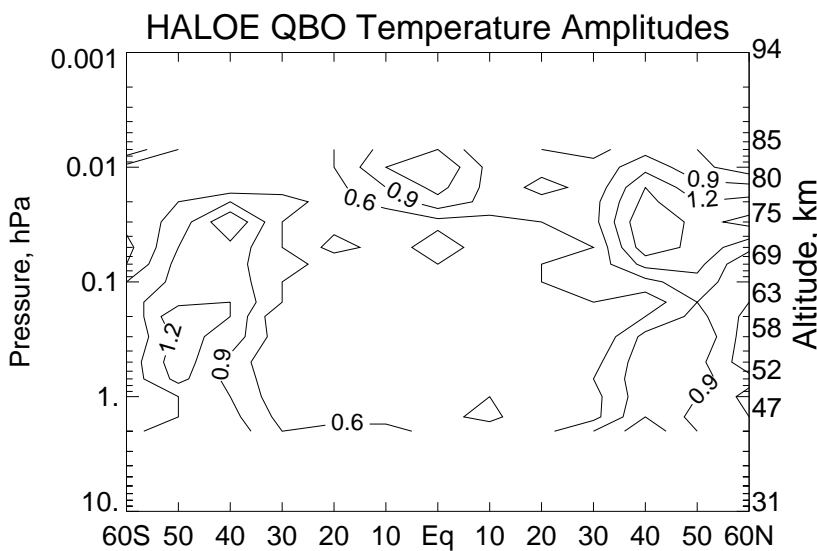

Fig. 10. Amplitudes for the $\mathrm{QBO}$ terms. Contour interval is $0.3 \mathrm{~K}$.

with those obtained in altitude coordinates from the SABER dataset in Huang et al. (2006, their Fig. 2). Both analyses indicate significant amplitudes at Equatorial latitudes of the upper mesosphere, although the HALOE results do not show the maximum at $70 \mathrm{~km}$ that was obtained from the SABER data. Tidal effects are large in the tropical upper mesosphere, and there may be issues with how well they have been accounted for by Huang et al. (2006); the SABER measurements experience a slow precession across nearly all local times during each 60-dy yaw cycle. For instance, Remsberg (2007) reported an average SS minus SR difference of nearly $-8 \mathrm{~K}$ for the upper mesosphere at the equator, and the time series data herein were adjusted for that difference for the present analyses. Even so, the HALOE residuals are much larger (or order $+/-5 \mathrm{~K}$ ) than the amplitude of its QBO term for the tropical upper mesosphere. Those differences between the MLR model values and the bin-averaged points do not change appreciably when the latitude bins are widened or when more profiles are required for an average. It is more likely that the rather large temperature fluctuations in the data are related to the variable nature of the occurrence, propagation from below, and breaking of the planetary and gravity waves (Baldwin et al., 2001).

HALOE shows increasing QBO amplitudes in the upper stratosphere near $2 \mathrm{hPa}$, although they are about half that obtained from the SABER analyses. Huang et al. (2006) also performed QBO analyses with the MLS dataset, but at constant pressure levels like the ones herein from HALOE, and they found an MLS QBO signal for the tropical upper stratosphere that is weaker than from SABER and more in line with the present values from HALOE.

Figure 11 shows the relative QBO phase at the equator and at $40 \mathrm{~N}$ and $40 \mathrm{~S}$. It is apparent that the atmospheric QBO signal is descending from the upper mesosphere to near the stratopause at each of the latitudes. There is a clear out-ofphase relationship from low to middle latitudes, and the QBO phase at the middle latitudes in nearly hemispherically sym-

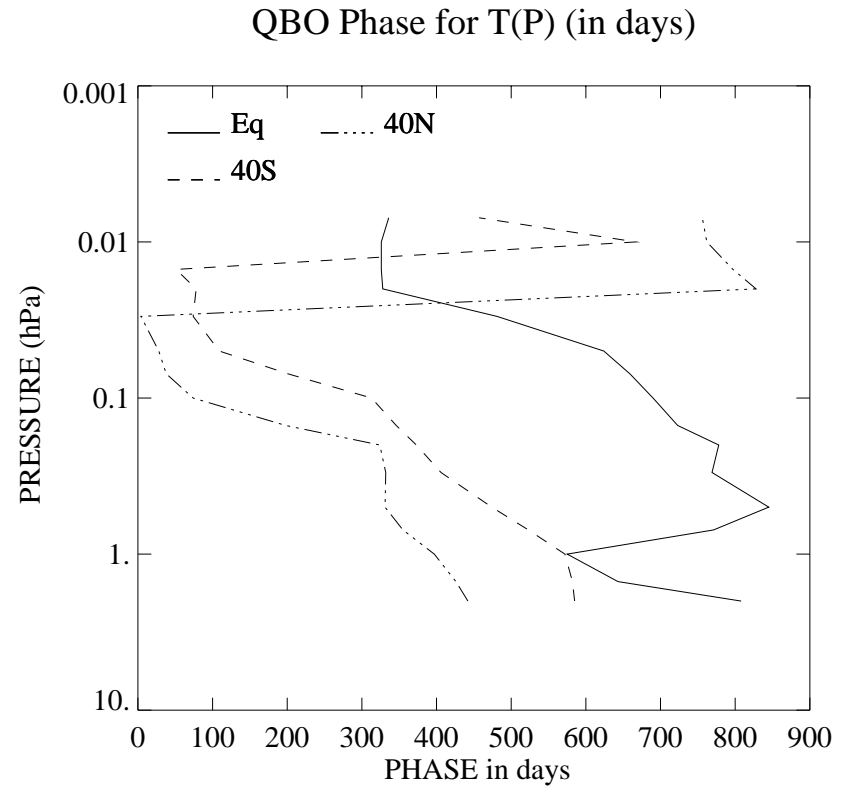

Fig. 11. Profiles of the relative phases for the QBO terms at selected latitudes.

metric. The rather abrupt change in the QBO phase at the equator near the stratopause may not be very significant because those QBO terms have amplitudes of only about $0.2 \mathrm{~K}$.

As noted earlier, the subbiennial (or IA) term arises due to interactions between the QBO cycle and the $\mathrm{AO}$ (and perhaps $\mathrm{SAO})$ cycles. The distribution of amplitudes for this term is shown in Fig. 12. Maxima occur in Fig. 12 at the equator near $0.015 \mathrm{hPa}$ and at 40 and 50 degrees near $0.07 \mathrm{hPa}$, and the subbiennial term is highly significant in those regions. Its phases are shown in Fig. 13 for the equator and for $40 \mathrm{~N}$ and $40 \mathrm{~S}$, and in general they are anti-symmetric between the two hemispheres. At the equator the subbiennial terms have a phase tilt that is opposite to that of the QBO term, although both terms are of very small amplitude throughout the middle mesosphere and are not highly significant. The distribution of this subbiennial term has not been reported heretofore for the mesosphere from any other satellite temperature datasets.

\section{Solar cycle and trend terms}

The findings for the seasonal and interannual terms of the preceding section are preliminary to the goal of analyzing the HALOE time series for its response to the solar cycle forcing and to a long-term cooling trend due to the increasing amounts of the atmospheric "greenhouse gases". Remsberg (2007) employed the MLR technique to resolve an SC-like term by assuming that it had an 11-yr period but then allowing the fit to the residuals to determine its phase. He labeled his approach as "exploratory" because he wanted to consider other possible decadal-scale forcings for 


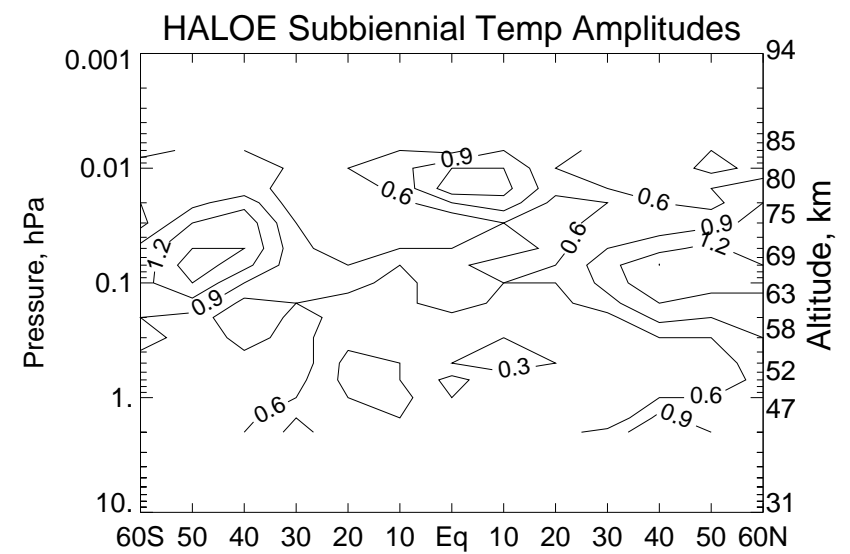

Fig. 12. Amplitudes for the subbiennial terms. Contour interval is $0.3 \mathrm{~K}$.

the temperature time series. In general, the time span for maximum solar flux conditions is broad and extends for several years. Instead of regressing directly against a standard solar flux proxy, he simply checked to see whether the phases of the SC-like terms that he found were within $\pm 2 \mathrm{yr}$ of January 1991 . The phases of the highly significant SC-like terms were tabulated in Remsberg (2007, his Table 11), and in most instances they are in-phase. Whenever the terms were nearly in-phase with a solar uv-flux proxy, he assumed that they were SC-like and due to the expected, direct solar-flux forcing mechanism. If the 11-yr term had amplitude that was considerably larger than expected and/or was not in-phase with the flux, he speculated that there was an additional, perhaps decadal-scale, dynamical forcing mechanism that was responsible.

In the present analysis the SC-like terms have since been determined at all the latitude and pressure-altitude grid points, even where those terms were not in-phase with the flux variations or where they were not so significant. A cosine weighting was applied to those SC-like amplitudes to account for the absolute time difference from January 1991 (or 2002) for the phase, as in Remsberg (2007). Then those adjusted amplitudes were multiplied by two to obtain an estimate of the "max minus min" SC temperature differences, as shown in Table 1. Negative values indicate where they are out of phase with those of a solar proxy having maximum flux at January 1991 (or 2002). Those circumstances occurred for a number of pressure levels in the middle mesosphere. This modified analysis provides values for generating a contour plot of the observed SC-like responses for comparison with the results from model simulations.

Figure 14 is a plot of those adjusted, SC-like (max minus min) differences for the latitude bins from $40 \mathrm{~S}$ to $40 \mathrm{~N}$. The $2 \sigma$ levels for those differences are of order $0.4 \mathrm{~K}$. Figure 15 is the contour plot of the phase for the response maximum as referenced to January 1991 (or January 2002); the shading shows the regions were the maximum is within 1.5

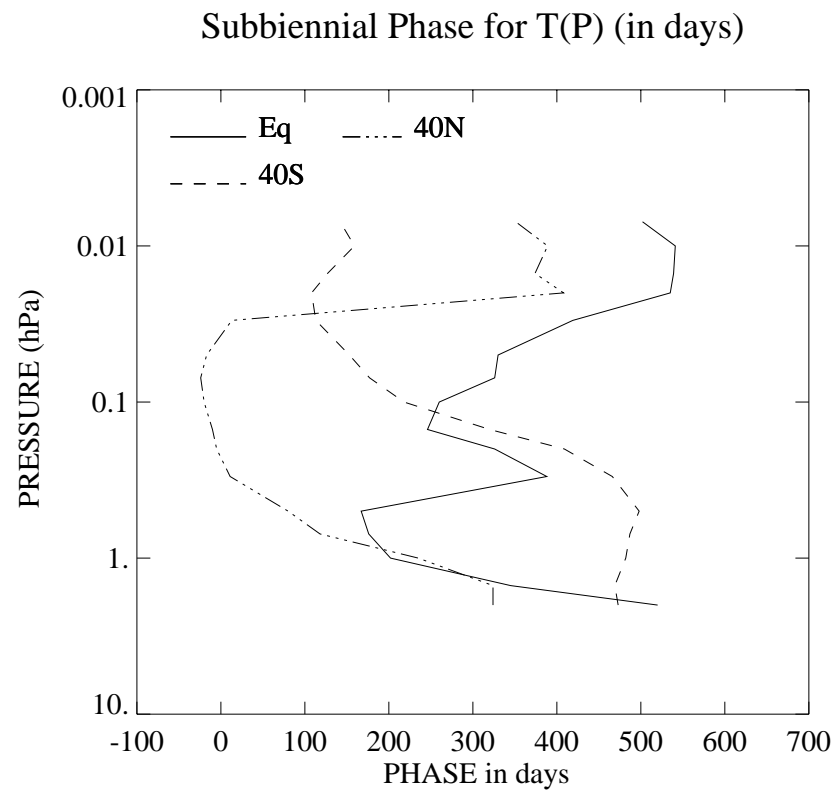

Fig. 13. Profiles of the relative phases for the subbiennial terms at selected latitudes.

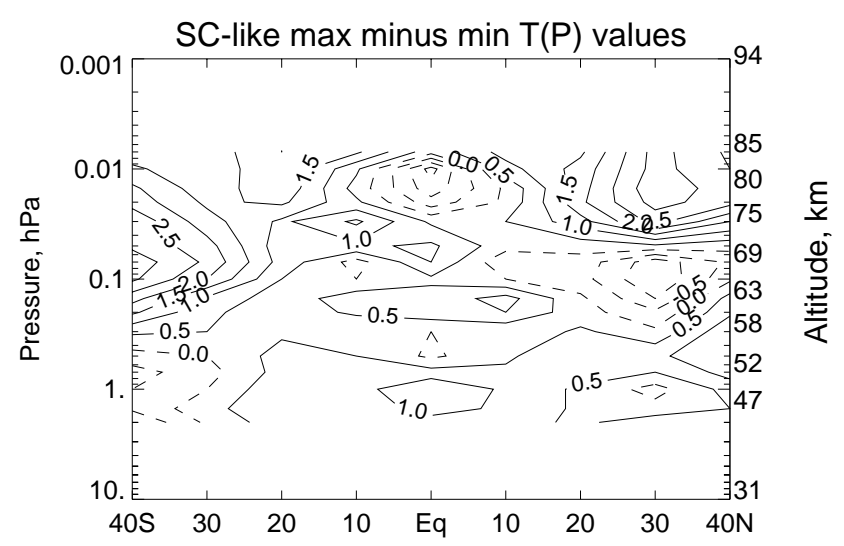

Fig. 14. Contour plot of the adjusted, SC-like "max minus min" $T(p)$ values. Contour interval is $0.5 \mathrm{~K}$, and the zero and negative contours are dashed.

years of that date. One can see that the response in Fig. 14 is generally weak in the mesosphere at low latitudes, although it attains a maximum value of greater than $1 \mathrm{~K}$ at the tropical stratopause. Response magnitudes become larger at middle latitudes. Figure 15 shows that the response is somewhat out-of-phase at the equator in the upper mesosphere, but it is in-phase at middle latitudes. At $30 \mathrm{~N}$ the response changes with pressure-altitude from in-phase to out-of-phase at about $0.05 \mathrm{hPa}$. The responses have a similar pattern at $40 \mathrm{~S}$, but the phase does not changeover until about $0.4 \mathrm{hPa}$. Responses are near zero in the upper stratosphere at middle latitudes. Overall, the patterns in Figs. 14 and 15 for the SC-like terms are considered qualitative. However, the 
Table 1. Adjusted, Max Minus Min, values of SC-like terms (K).

\begin{tabular}{crrrrrrrrrrrrr}
\hline$P(\mathrm{hPa})$ & $60 \mathrm{~S}$ & $50 \mathrm{~S}$ & $40 \mathrm{~S}$ & $30 \mathrm{~S}$ & $20 \mathrm{~S}$ & $10 \mathrm{~S}$ & $\mathrm{Eq}$ & $10 \mathrm{~N}$ & $20 \mathrm{~N}$ & $30 \mathrm{~N}$ & $40 \mathrm{~N}$ & $50 \mathrm{~N}$ & $60 \mathrm{~N}$ \\
\hline 0.007 & 1.5 & 2.5 & 1.2 & 1.2 & 2.0 & 1.6 & 0.2 & 1.2 & 1.4 & 3.2 & 2.4 & 2.8 & 3.8 \\
0.010 & 1.2 & 2.2 & 1.6 & 1.1 & 2.0 & 0.6 & -1.7 & 0.8 & 1.7 & 3.2 & 2.5 & 3.0 & 4.2 \\
0.015 & 0.5 & 2.2 & 2.1 & 1.2 & 1.9 & 0.3 & -1.3 & 0.1 & 1.8 & 3.4 & 2.7 & 3.2 & 4.3 \\
0.020 & 0.1 & 2.2 & 2.3 & 1.4 & 1.6 & 0.6 & -0.8 & 0.1 & 1.9 & 3.2 & 2.7 & 3.2 & 4.3 \\
0.030 & -0.7 & 2.2 & 2.9 & 1.7 & 0.9 & 1.6 & 0.4 & 0.5 & 1.3 & 2.7 & 1.5 & 2.6 & 3.7 \\
0.050 & -1.6 & 1.2 & 2.9 & 2.2 & 0.7 & 0.9 & 1.1 & 0.2 & 0.2 & 0.4 & 0.2 & 0.1 & 2.9 \\
0.070 & -1.8 & 0.6 & 3.3 & 2.4 & 0.8 & -0.2 & 1.0 & -0.4 & -0.2 & -1.3 & -0.4 & 0.5 & 1.5 \\
0.100 & -1.1 & 1.1 & 3.1 & 2.0 & 0.5 & 0.0 & 0.4 & 0.0 & -0.3 & -1.5 & -0.1 & 0.7 & 0.6 \\
0.150 & -0.1 & 1.8 & 2.2 & 0.9 & 0.2 & 0.8 & 0.7 & 1.2 & 0.1 & -1.0 & 0.7 & 1.5 & 0.4 \\
0.200 & 0.6 & 2.2 & 1.6 & 0.6 & 0.2 & 0.6 & 0.8 & 1.0 & 0.2 & -0.4 & 0.9 & 1.6 & 0.3 \\
0.300 & 1.5 & 2.2 & 0.6 & 0.5 & 0.4 & 0.0 & 0.0 & 0.1 & 0.6 & 0.1 & 1.4 & 1.5 & 0.1 \\
0.500 & 1.7 & 1.6 & -0.2 & 0.0 & 0.7 & 0.5 & -0.1 & 0.4 & 1.0 & 0.9 & 1.4 & 0.6 & 0.4 \\
0.700 & 1.9 & 1.5 & -0.7 & -0.2 & 0.7 & 0.7 & 0.7 & 0.6 & 0.8 & 0.5 & 1.2 & 0.2 & 0.0 \\
1.000 & 1.8 & 1.2 & -0.5 & 0.0 & 0.9 & 0.8 & 1.5 & 0.9 & 0.4 & -0.2 & 0.7 & -0.5 & -0.0 \\
1.500 & 1.5 & 0.4 & -0.4 & 0.3 & 1.0 & 0.7 & 1.2 & 0.9 & 0.4 & 0.2 & 0.5 & -0.8 & -0.8 \\
2.000 & 1.4 & 0.2 & -1.0 & 0.1 & 0.8 & 0.7 & 0.8 & 0.7 & 0.4 & 0.8 & 0.8 & -0.7 & -1.3 \\
\hline
\end{tabular}

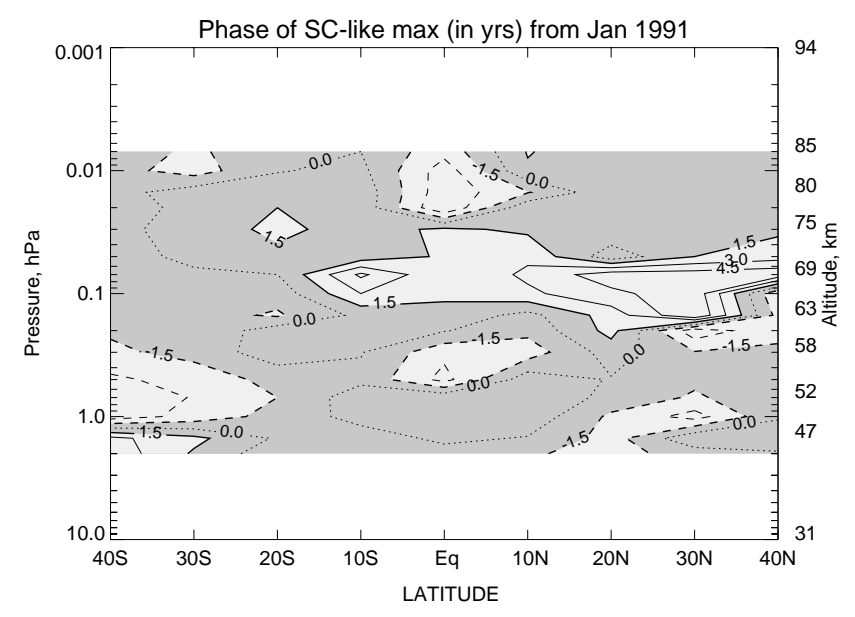

Fig. 15. Contour plot of the phase of the SC-like maximum (in years) as referenced to January 1991. The shaded regions have a phase maximum within $\pm 1.5 \mathrm{yrs}$ of that date. Contour interval is 1.5 years. Negative values are dashed and the zero contour is dotted.

larger SC-like responses are in-phase, clearly present in the HALOE time series, and highly significant. The responses in Table 1 at 50 and 60 degrees latitude are considered less meaningful because of the poorer seasonal sampling from HALOE at high latitudes. Those SC-like results were not plotted, although there is reasonable continuity for them from 40 to 50 degrees for many of the pressure levels.

Most of the early model simulations of the response of mesospheric $T(p)$ to a direct, solar uv-flux forcing indicate weak increases with altitude and latitude (e.g. Garcia et al., 1984; Huang and Brasseur, 1993; Shindell et al., 1999; Khosravi et al., 2002). At low latitudes their modeled responses have minimum values in the low to mid mesosphere but increase near the stratopause and in the uppermost mesosphere. The HALOE results at low latitudes in Table 1 agree with the models except in the uppermost mesosphere. The analyzed, HALOE “max minus min" SC responses of 0.7 to $1.5 \mathrm{~K}$ near the tropical stratopause agree with the recent analyses from the ERA-40 dataset (Crooks and Gray, 2005) and from the separate analyses of the HALOE data by Fadnavis and Beig (2006a). The observed responses from HALOE also agree with those from more recent model studies (e.g. Hampson et al., 2005; Matthes et al., 2004; Marsh et al., 2007).

HALOE SC-like responses in Fig. 14 show an alternating phase relationship with altitude for the mesosphere at middle latitude and for both hemispheres. However, the pattern of the response is shifted to higher altitudes for the northern than for the Southern Hemisphere. The modeled results of Matthes et al. (2004) and especially of Marsh et al. (2007) also show larger SC responses at middle latitudes. They agree well with the HALOE results for the southern, but not for the Northern Hemisphere. It is postulated that the somewhat larger HALOE responses at the higher altitudes of the Northern Hemisphere are associated with a decadal-scale, dynamical response that is also in-phase with the solar flux forcing but which is not yet represented well in the models.

The MLR technique can accommodate a simultaneous fitting of polynomial terms to the HALOE time series, in addition to all the foregoing periodic terms. If the analyzed trends are reasonable, they provide an independent check of the fidelity of the SC-like terms, too. Temperature trends are determined by changes for both $\mathrm{CO}_{2}$ and $\mathrm{O}_{3}$ in the upper stratosphere and lower mesosphere, but primarily for $\mathrm{CO}_{2}$ in the middle and upper mesosphere. The HALOE measurements were obtained for a time span when the trends in ozone 
were small for the upper stratosphere, but when $\mathrm{CO}_{2}$ was still increasing steadily (WMO, 2007). Therefore, it was assumed that a linear trend term ought to give a reasonable fit to any trends in the HALOE $T(p)$ time series.

Remsberg (2007) found highly significant linear trends at a number of latitudes and pressure-altitudes, and those trends are still valid. The trend terms of lower significance have been added for this present study, so that comparisons with model results can be made more easily. It is also noted that there were very large trends due to "end point" anomalies for several levels of the higher latitude zones of 50 and 60 degrees, apparently because the seasonal sampling was not good toward the end of the HALOE mission. The results shown herein are restricted to the latitude range of $40 \mathrm{~S}$ to $40 \mathrm{~N}$.

A contour plot of the trends is shown in Fig. 16, and their $2 \sigma$ values are of order $0.2 \mathrm{~K} / \mathrm{decade}$. The trends are small throughout the mesosphere at low latitudes. In fact, they are slightly positive at low latitudes of the upper mesosphere and at the middle latitudes of the lower mesosphere. These are the same regions where the solar cycle responses are also weak. Simulations of the rate of cooling due to the increasing "greenhouse gases" are in general agreement with cooling rates of $-0.5 \mathrm{~K} /$ decade for the mesosphere, particularly if the only gas that is changing is $\mathrm{CO}_{2}$ (e.g. Akmaev et al., 2006). In the uppermost mesosphere the observed trends decrease to near zero across all the latitude zones and are in good agreement with the simulations of Garcia et al. (2007). There is a clear increase in the observed cooling trends in the middle to upper mesosphere at the middle latitudes of both hemispheres (of order $-2.0 \mathrm{~K} /$ decade), and those values are highly significant. However, the simulation studies are not reproducing that finding. Clearly, there must be other mechanisms contributing to the diagnosed cooling trends from the HALOE data at middle latitudes of the upper mesosphere.

Trends in Fig. 16 near the stratopause are fairly uniform with latitude and of order -0.5 to $-1.0 \mathrm{~K} /$ decade. They agree with those reported for the low latitudes by Fadnavis and Beig (2006b). These cooling rates are also within the range of model results in Shine et al. (2003). Akmaev et al. (2006) calculated somewhat larger global cooling rates of about $-2 \mathrm{~K} /$ decade near the stratopause. However, their results are for the period 1980-2000, when the decline in ozone (and the decline in its radiative heating) was contributing to their calculated net cooling values. The HALOE measurements were taken when the decline of the ozone was much less or near zero. Trends in upper stratospheric temperatures have not been reported from other datasets for comparisons with the specific period of HALOE - 1991-2005.

\section{Discussion and summary}

The findings herein represent new results for the SC-like and trend terms of $T(p)$ since the review by Beig et al. (2003),

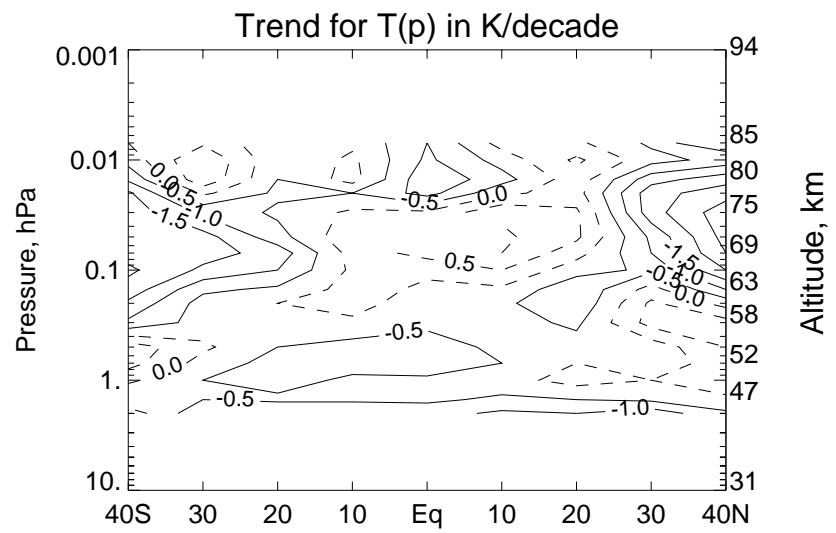

Fig. 16. Contour plot of the diagnosed, linear trend terms (in $\mathrm{K} /$ decade) from HALOE. Contour interval is $0.5 \mathrm{~K} /$ decade, and the zero and positive (warming) trends have dashed contours.

and in many respects there is good agreement with the results from models. However, the SC-like responses and trends from HALOE for the middle latitudes of the upper mesosphere are definitely larger than those from the models. This region is where planetary waves tend to break, particularly for the winter/spring period. Gravity waves and tides also begin to break in the upper mesosphere, and it is a region of observed mesospheric inversion layers (MIL). The propagation of planetary waves to the mesosphere may be enhanced under solar maximum conditions, giving rise to an additional $T(p)$ response that is in-phase with the solar cycle. For example, Kirkwood and Stebel (2003) reported a decadal-scale correlation for the phase of the stationary planetary waves and their associated effects on the net circulation for the occurrence of noctilucent clouds (NLC) near the polar summer mesopause. The solar response from HALOE in the upper mesosphere at middle latitudes indicates that the coldest temperatures are occurring near solar minimum when the water vapor (and NLC sightings?) is at a maximum in that region (Chandra et al., 1997). It is reasonable to expect that such wave-induced forcings are affecting the $T(p)$ at middle latitudes of the upper mesosphere, as well.

There have been several recent modeling studies of a dynamical response to the solar cycle forcing that indicate a reinforcement of the normal radiative temperature response in the mesosphere at solar maximum (Kodera and Kuroda, 2002; Hampson et al., 2005). Koshravi et al. (2002) conducted 2-D model simulations to see whether they could produce a dynamically-induced temperature response to the solar flux forcing. They found significant, in-phase temperature responses to the SC of several $\mathrm{K}$, particularly in the winter hemisphere of the upper mesosphere. Schmidt et al. (2006) also found SC-like responses of order $3 \mathrm{~K}$ near the mesopause from their 3-D model simulations, but weakening to less than $1 \mathrm{~K}$ below $75 \mathrm{~km}$. Such a rapid decline toward lower altitudes is in reasonable accord with profiles 
of the SC-like response from HALOE for middle latitudes (Fig. 14). There is also a decadal-scale, response in $T(p)$ at $50-60 \mathrm{~N}$ in the upper stratosphere that is out-of-phase with the solar forcing (see Table 1 and also Remsberg, 2007, his Table 11). It is speculated that this character is an indirect radiative and dynamical response to effects of the solar forcing at adjacent altitudes and/or lower latitudes.

Schmidt et al. (2006) and Fomichev et al. (2007) find that the cooling due to the increases in $\mathrm{CO}_{2}$ is somewhat larger for the middle than the low latitudes of the upper mesosphere, but with some seasonal dependence - in qualitative agreement with the annual average results from HALOE in Fig. 16. Gruzdev and Brasseur (2005) used an interactive 2-D model to investigate trends in $T(p)$ due to increasing "greenhouse gases". Although their results were similar to those of Schmidt et al. (2006) and Fomichev et al. (2007), they point out that there can also be long-term changes in $T(p)$ due to the dynamics and the gravity wave activity that should be associated with the changes in the thermal structure due to the concurrent radiative and chemical processes.

To summarize, 14-year time series of HALOE SR and SS $T(p)$ data have been analyzed for their seasonal, interannual, $\mathrm{SC}$-like, and trend terms from $60 \mathrm{~S}$ to $60 \mathrm{~N}$ and from $2 \mathrm{hPa}$ to $0.007 \mathrm{hPa}$. The seasonal and annual mean terms have reasonable amplitudes and phases and can be used to generate a seasonal, zonal average climatology for a given latitude zone. Two interannual terms (QBO-like and sub-biennial) are prominent at most of the latitudes and pressure-altitudes. Significant SC-like and trend terms were also found from the analyses at many, but not all locations. The SC-like terms are generally in-phase with the solar flux forcing and have amplitudes in the tropics that agree with most model results. There is an increasing SC-like response from low to middle latitudes of the upper mesosphere that is presumed to be due to decadal-scale, dynamical processes that are also inphase with the solar forcing. The observed cooling trends that have been resolved are in general agreement with those from several radiative/dynamical models of the effects of the increasing amounts of atmospheric $\mathrm{CO}_{2}$ in the mesosphere and upper stratosphere at the low latitudes, although they are larger than the model results at middle latitudes of the upper mesosphere.

Acknowledgements. The author is grateful to have had the opportunity to present these findings at the 4th Workshop for the Climate and Weather of the Sun-Earth System (CAWSES) held in Sodankyla, Finland, in September 2006. He also expresses his appreciation to J. Russell (HALOE - Principal Investigator) and to the members of the HALOE Project Team for producing and characterizing its high quality dataset. The analyses herein were supported with funds for the UARS HALOE Project administered by C. Jackman of NASA/GSFC and by M. Kurylo of NASA/Hdqtrs.

Topical Editor U.-P. Hoppe thanks two anonymous referees for their help in evaluating this paper.

\section{References}

Akmaev, R. A., Fomichev, V. I., and Zhu, X.: Impact of middleatmospheric composition changes on greenhouse cooling in the upper atmosphere, J. Atmos. Solar Terr. Phys., 68, 1879-1889, doi:10.1016/j.jastp.2006.03.008, 2006.

Baldwin, M. P., Gray, L. L., Dunkerton, T. J., et al.: The quasibiennial oscillation, Rev. Geophys., 39, 179-229, 2001.

Barnett, J. J., Corney, M., and Labitzke, K.: Annual and semiannual cycles based on the middle atmosphere reference model in Section 2.2, in: Handbook for Middle Atmosphere Program (MAP), vol. 16, edited by: Labitzke, K., Barnett, J. J., and Edwards, B., SCOSTEP Secretariat, U. of Illinois, Urbana, IL, 175-180, 1985.

Beig, G., P., Keckhut, P., Lowe, R. P., et al.: Review of mesospheric temperature trends, Rev. Geophys., 41, 1015, 1-1-1-41, doi:10.1029/2002RG000121, 2003.

Burrage, M. D., Vincent, R. A., Mayr, H. G., Skinner, W. R., Arnold, N. F., and Hays, P. B.: Long-term variability of the equatorial middle atmosphere zonal wind, J. Geophys. Res., 101, 12 847-12 854, 1996.

Chandra, S., Jackman, C. H., Fleming, E. L., and Russell III, J. M.: The seasonal and long-term changes in mesospheric water vapor, Geophys. Res. Lett., 24, 639-642, 1997.

Crooks, S. A. and Gray, L. J.: Characterization of the 11-year solar signal using a multiple regression analysis of the ERA-40 dataset, J. Climate, 18, 996-1015, 2005.

Dunkerton, T. J.: Quasi-biennial and subbiennial variations of stratospheric trace constituents derived from HALOE observations, J. Atmos. Sci., 58, 7-25, 2001.

Fadnavis, S. and Beig, G.: Decadal solar effects on temperature and ozone in the tropical stratosphere, Ann. Geophys., 24, 20912103, 2006a, http://www.ann-geophys.net/24/2091/2006/.

Fadnavis, S. and Beig, G.: Seasonal variation of trend in temperature and ozone over the tropical stratosphere in the northern hemisphere, J. Atmos. Solar Terr. Phys., 68, 1952-1961, doi:10.1016/j.jastp.2006.09.003, 2006b.

Fleming, E. L., Chandra, S., Barnett, J. J., and Corney, M.: Zonal mean temperature, pressure, zonal wind and geopotential height as functions of latitude, Adv. Space Res., 10, (12)11-12(59), 1990.

Fomichev, V. I., Jonsson, A. I., DeGrandpre, J., Beagley, S. R., McLandress, C., Semeniuk, K., and Shepherd, T. G.: Response of the middle atmosphere to $\mathrm{CO}_{2}$ doubling: results from the Canadian middle atmosphere model, J. Climate, 20, 1121-1144, 2007.

Garcia, R. R., Solomon, S., Roble, R. G., and Rusch, D. W.: A numerical response of the middle atmosphere to the 11-year solar cycle, Planet. Space Sci., 32, 411-423, 1984.

Garcia, R. R., Marsh, D. R., Kinnison, D. E., Boville, G. A., and Sassi, F.: Simulation of secular trends in the middle atmosphere, 1950-2003, J. Geophys. Res., 112, D09301, doi:10.1029/2006JD007485, 2007.

Gordley, L. L., Hervig, M. E., Thompson, R. E., Magill, B. E., Russell, J. M., and Remsberg, E. E.: Detector nonlinearity effects on the HALOE data (preliminary results), Eos Trans. AGU, 87(52), Fall Meet. Suppl., Abstract A21F-0908, 2006.

Gruzdev, A. N. and Brasseur, G. P.: Long-term changes in the mesosphere calculated by a two-dimensional model, J. Geophys. Res., 110, D03304, doi:10.1029/2003JD004410, 2005. 
Hampson, J., Keckhut, P., Hauchecorne, A., and Chanin, M. L.: The effect of the 11-year solar-cycle on the temperature in the upper-stratosphere and mesosphere - Part III: Investigations of zonal asymmetry, J. Atmos. Solar Terr. Phys., 68(14), 15911599, doi:10.1016/j.jastp.2006.05.006, 2006.

Hampson, J., Keckhut, P., Hauchecorne, A., and Chanin, M. L.: The effect of the 11-year solar-cycle on the temperature in the upper-stratosphere and mesosphere - Part II, Numerical simulations and the role of planetary waves, J. Atmos. Solar Terr. Phys., 67(11), 948-958, doi:10.1016/j.jastp.2005.03.005, 2005.

Huang, T. Y. W. and Brasseur, G. P.: Effect of long-term solar variability in a two-dimensional interactive model of the middle atmosphere, J. Geophys. Res., 98, 20 413-20 427, 1993.

Huang, F. T., Mayr, H. G., Reber, C. A., Russell, J. M., Mlynczak, M., and Mengel, J. G.: Stratospheric and mesospheric temperature variations for the quasi-biennial and semiannual (QBO and SAO) oscillations based on measurements from SABER (TIMED) and MLS (UARS), Ann. Geophys., 24, 2131-2149, 2006 ,

http://www.ann-geophys.net/24/2131/2006/.

Kawamoto, N. and Shiotani, M.: Interannual variability of the vertical descent rate in the Antarctic polar vortex, J. Geophys. Res., 105, 11 935-11946, 2000.

Keckhut, P., Cagnazzo, C., Chanin, M.-L., Claud, C., and Hauchecorne, A.: The 11-year solar-cycle effects on the temperature in the upper-stratosphere and mesosphere: Part I - Assessment of observations, J. Atmos. Solar Terr. Phys., 67(11), 940-947, doi:10.1016/j.jastp.2005.01.008, 2005.

Khosravi, R., Brasseur, G., Smith, A., Rusch, D., Walters, S., Chabrillat, S., and Kockarts, G.: Response of the mesosphere to human-induced perturbations and solar variability calculated by a 2-D model, J. Geophys. Res., 107(D18), 4358, doi:10.1029/2001JD001235, 2002.

Kirkwood, S. and Stebel, K.: Influence of planetary waves on noctilucent cloud occurrence over NW Europe, J. Geophys. Res., 108, 108(D8), 8440, doi:10.1029/2002JD002356, 2003.

Kodera, K. and Kuroda, Y.: Dynamical response to the solar cycle, J. Geophys. Res., 107(D24), 4749, doi:10.1029/2002JD002224, 2002.

Kubicki, A., Keckhut, P., Chanin, M.-L., Hauchecorne, A., Lysenko, E., and Golitsyn, G. S.: Temperature trends in the middle atmosphere as seen by historical Russian rocket launches: Part 1, Volgograd (48.68 N, 44.35 E), J. Atmos. Solar Terr. Phys., 68(10), 1075-1086, doi:10.1016/j.jastp.2006.02.001, 2006.

Laštovička, J., Akmaev, R. A., Beig, G., Bremer, J., and Emmert, J. T.: Global change in the upper atmosphere, Science, 314, 12531254, 2006.

Leblanc, T., McDermid, I. S., Keckhut, P., Hauchecorne, A., She, C.-Y., and Kreuger, D. A.: Temperature climatology of the middle atmosphere from long-term lidar measurements at middle and low latitudes, J. Geophys. Res., 104, 17 191-17 204, 1998.

Marsh, D. R., Garcia, R. R., Kinnison, D. E., Boville, B. A., Sassi, F., Solomon, S. C., and Matthes, K.: Modeling the whole atmosphere response to solar cycle changes in radiative and geomagnetic forcing, J. Geophys. Res., 112, D23306, doi:10.1029/2006JD008306, 2007.
Matthes, K., Langematz, U., Gray, L. L., Kodera, K., and Labitzke, K.: Improved 11-solar signal in the Freie Universitat Berlin Climate Middle Atmosphere Model (FUB-CMAM), J. Geophys. Res., 109, D06101, doi:10.1029/2003JD004012, 2004.

Randel, W., Udelhofen, P., Fleming, E., et al.: The SPARC Intercomparison of middle atmosphere climatologies, J. Climate, 17, 986-1003, 2004.

Remsberg, E. E.: A re-analysis for the seasonal and longerperiod cycles and the trends in middle atmosphere temperature from HALOE, J. Geophys. Res., 112, D09118, doi:10.1029/2006JD007489, 2007.

Remsberg, E. E. and Deaver, L. E.: Interannual, solar cycle, and trend terms in middle atmospheric temperature time series from HALOE, J. Geophys. Res., 110, D06106, doi:1029/2004JD004905, 2005.

Remsberg, E., Lingenfelser, G., Harvey, V. L., Grose, W., Russell III, J., Mlynczak, M., Gordley, L., and Marshall, B. T.: On the verification of the quality of SABER temperature, geopotential height, and wind fields by comparison with Met Office assimilated analyses, J. Geophys. Res., 108(D20), 4628, doi:10.1029/2003JD003720, 2003.

Remsberg, E. E., Deaver, L., Wells, J., et al.: An assessment of the quality of Halogen Occultation Experiment temperature profiles in the mesosphere based on comparisons with Rayleigh backscatter lidar and inflatable falling sphere measurements, J. Geophys. Res., 107(D20), 4447, doi:10.1029/2001JD001521, 2002.

Remsberg, E. E., Bhatt, P. P., and Deaver, L. E.: Ozone changes in the lower stratosphere from the Halogen Occultation Experiment for 1991 through 1999, J. Geophys. Res., 106, 1639-1653, 2001.

Remsberg, E. E., Bhatt, P. P., and Miles, T.: An assessment of satellite temperature distributions used to derive the net diabatic transport for zonally averaged models of the middle atmosphere, J. Geophys. Res., 99, 23 001-23 017, 1994.

Russell III, J. M., Gordley, L. L., Park, J. H., et al.: The halogen occultation experiment, J. Geophys. Res., 98, 10777-10 797, 1993.

Schmidt, H., Brasseur, G. P., Charron, M., et al.: The HAMMONIA chemistry climate model: sensitivity of the mesopause region to the 11-year solar cycle and $\mathrm{CO}_{2}$ doubling, J. Climate, 19, 39033931, 2006.

Shepherd, M. G., Shepherd, G. G., Evans, W. F. J., and Sridharan, S.: Global variability of mesospheric temperature: planetaryscale perturbations at equatorial and tropical latitudes, J. Geophys. Res., 110, D24103, doi:10.1029/2005JD006128, 2005.

Shepherd, M. G., Evans, W. F. J., Hernandez, G., Offermann, D., and Takahashi, H.: Global variability of mesospheric temperature: mean temperature field, J. Geophys. Res., 109, D24117, doi:10.1029/2004JD005054, 2004.

Shindell, D., Rind, D., Balachandran, N., Lean, J., and Lonergan, P.: Solar cycle variability, ozone, and climate, Science, 284, 305308, 1999.

Shine, K. P., Bourqui, M. S., Forster, P. M. D., et al.: A comparison of model-simulated trends in stratospheric temperatures, Q. J. Roy. Meteorol. Soc., 129, 1565-1588, 2003.

WMO: Scientific assessment of ozone depletion: 2006, Global Ozone Research and Monitoring Project, Report No. 50, 572 pp., Geneva, Switzerland, 2007. 